ASLI QoL 2021

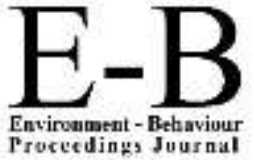

Procecding, Juurnal

\section{AQoL2021LangkawiIsland}

https://www.amerabra.org; https://fspu.uitm.edu.my/cebs; https://www.emasemasresources.com/ $5^{\text {th }}$ ABRA International Conference on Quality of Life Holiday Villa Langkawi, Langkawi Island, Malaysia, 15-16 Dec 2021

\title{
Indoor Thermal Assessment of Medium-Cost House in Arid Climate
}

\author{
Abdulbasit Almhafdy \\ Department of Architecture, College of Architecture and Planning, \\ Qassim University, Qassim, 52571, Saudi Arabia

\begin{abstract}
An environmental responsive design of building internal spaces is an important criterion and should be taken into account in the pre-design stage of the residential buildings. This study aims to analyze the existing spatial spaces of a residential building in terms of thermal performance in a hot arid climate area. Temperature data loggers were utilized in the duplex house. Results indicate that wall exposure, window size, floor level and orientation are the key to design a friendly environment of internal spaces. The neighbourhood fabric has an important role in terms of shadows and time of direct exposure to radiation.
\end{abstract}

Keywords: Indoor house, Arid climate, Air temperature, spatial design

eISSN: 2398-4287@ 2021. The Authors. Published for AMER ABRA cE-Bs by e-International Publishing House, Ltd., UK. This is an open access article under the CC BYNC-ND license (http://creativecommons.org/licenses/by-nc-nd/4.0/). Peer-review under responsibility of AMER (Association of Malaysian Environment-Behaviour Researchers), ABRA (Association of Behavioural Researchers on Asians/Africans/Arabians) and CE-Bs (Centre for Environment-Behaviour Studies), Faculty of Architecture, Planning \& Surveying, Universiti Teknologi MARA, Malaysia.

DOI: https://doi.org/10.21834/ebpj.v6i18.3076

\subsection{Introduction}

The call for serious remedies of internal house spaces was raised for another crisis that has stood before people in the last two years, the COVID-19 pandemic (Xu et al., 2020). The World Health Organization (WHO) and many governments have recommended and implemented home quarantine as a response to the COVID-19 outbreak which affects people in many aspects (Akbari et al., 2021). Thoughtful ideas such as airtightness (Fernández-Agüera et al., 2019), occupant satisfaction (Licina \& Yildirim, 2021) and occupantcentric control(Kong et al., 2022) for the house design aspect have been taken into consideration by local architects, designers, and households to overcome the energy demand caused by the home lockdown (Aldubyan \& Krarti, 2022)(Fernández-Agüera et al., 2019). Inadequate passive design strategies will have an impact on the indoor thermal condition and, as a result, thermal comfort. As stated by the WHO, improving the indoor environment for buildings has a good impact on human health and minimizes negative psychological stress (Akbari et al., 2021). With the latest WHO quarantine imposed because to COVID-19, this could greatly aid occupation. On the other hand, according to US Environmental Protection Agency (USEPA, 2013), People spend most of their time (up to 90\%) inside buildings and, therefore, the indoor environmental quality has a significant impact on their quality of life (Hailu et al., 2021). Besides, the rapid development of construction in the residential building due to the long-term investments raised the importance of energy consumption in Saudi Arabia (Asif, 2016). Buildings are responsible for $40 \%$ of world energy use and $30 \%$ of total $\mathrm{CO}_{2}$ emissions (AlHomoud \& Krarti, 2021). Many international energy efficiency efforts have enhanced the reduction of energy use in buildings compared to the increase of buildings population (Abd-ur-Rehman et al., 2018). Buildings and other developments can potentially harm the

eISSN: 2398-4287C 2021. The Authors. Published for AMER ABRA cE-Bs by e-International Publishing House, Ltd., UK. This is an open access article under the CC BYNC-ND license (http://creativecommons.org/licenses/by-nc-nd/4.0/). Peer-review under responsibility of AMER (Association of Malaysian Environment-Behaviour Researchers), ABRA (Association of Behavioural Researchers on Asians/Africans/Arabians) and cE-Bs (Centre for Environment-Behaviour Studies), Faculty of Architecture, Planning \& Surveying, Universiti Teknologi MARA, Malaysia. 
environment due to inefficient resource use and inadequate waste management. As a result, building energy efficiency is crucial in order to reduce energy consumption and promote local environmental sustainability. For that reason, there is a need to conduct an environmental assessment for various house spaces especially in a harsh climate like Qassim region in Saudi Arabia. The demand for electrical energy in Saudi Arabia has increased significantly during the last decade (from 218 TWh in 2010 to 300 TWh in 2018) (Ghamdi, 2020). According to annual statistics from the Saudi Arabian Monetary Authority, the residential sector consumed around half of the country's total electricity from 2005 to 2018 . Moreover, as a result of increased population and economic growth, energy demand is rapidly increasing at a rate of $5-8 \%$ annually, and it is predicted to increase by $50 \%$ between 2020 and 2023 .

The Saudi Building Code National Committee has introduced a new Saudi Building Code 601 (SBC) for residential buildings. The SBC has been imposed in the buildings industry as the start of July 2021, however, until now, around $33 \%$ of the new house were built according to the previous code (Saudi Code 2007)(Saudi Energy Efficiency Center, n.d.)(Alayed et al., 2021)(Abdul Mujeebu \& Alshamrani, 2016). Besides, around $70 \%$ of current houses were built without any consideration of thermal insulation (Alwetaishi \& Benjeddou, 2021). These issues, as a consequence, result in a significant increase in energy consumption for the approximately 5.5 million existing houses, specifically for cooling demand in a climate like Saudi Arabia. The extreme usage of cooling is related to the intense heat during the summer, which needs nearly $70 \%$ of the total electric energy consumed in buildings in Saudi Arabia. Furthermore, more than $77 \%$ of Saudi Arabia electricity is consumed by buildings sectors and $50 \%$ of that portion goes for housing. There is an intention outlined by the Saudi Arabian government to reduce energy use by $30 \%$ by 2030 (2030 Vision, 2020). Climate responses of the internal design of building spaces could be one of the main solutions that scholars should be addressed first. Besides the main functions of internal spaces of residential buildings. Many houses in the Middle East and, particularly in Saudi Arabia, have various functions including gathering areas "Dewania", "Mashab" and "Mogalad" and all are mainly for family, relatives and neighbours gathering at different times of the day.

The aim of this paper is to conduct an indoor assessment of the thermal performance of existing houses in a hot arid climate in Saudi Arabia. This will help architects and designers to understand how the environmental responsive design approach of house indoor should be done.

As seen in Figure 2, all zones have a high demand for cooling and thus, immediate remedies need to be taken to improve the energy efficiency. The spatial design of housing can significantly affect indoor thermal. This paper will conduct field measurement as the main method for thermal assessment of existing houses in the Qassim region, Saudi Arabia.

\subsection{Objective}

The main objective of this study is to highlight how indoor thermal performance could affect the spatial design of house spaces in the hot arid climate.

\subsection{Methodology}

In order to investigate the indoor thermal behaviour of house in a hot arid climate like Qassim region, ongoing thermal measurement was conducted as a quantitative analysis of 24 hours on a typical hot day of the year.

\subsection{The case study}

The in-house field measurements were performed on medium-cost detached house located in the Qassim region at Buraydah city. The house has four bedrooms, one guest room, living room, office room, Mashab and outdoor terrace. The Mashab room is a special guest room that is usually used during winter as it has an area for lighting a fire. This room is also designed with one fully glazed side with access to the terrace or garden area. The spaces which are subjected to data collections are listed in Table 1.

\subsection{Equipment calibration and field measurements.}

A typical house medium-cost level was selected to measure the thermal condition for 24 hours on the $15^{\text {th }}$ of August. As seen in Table 1 , seven thermal devices of Onset HOBO data logger were used in various rooms of the house. Three devices of thermal heat stress TWL were used in the gathering area i.e. living room, guest room and outdoor gathering terrace.

Table 1. Case study details and data logger locations

\begin{tabular}{|c|c|c|c|c|c|c|c|c|}
\hline \multirow{2}{*}{ Floors } & \multirow{2}{*}{ Spaces } & \multirow{2}{*}{ Data Logger } & \multicolumn{3}{|c|}{ External Walls orientation $\left(\mathrm{m}^{2}\right)$} & \multicolumn{2}{|c|}{ Window $(\%)$} & \multirow{2}{*}{$\begin{array}{c}\text { Top roof } \\
\left(\mathrm{m}^{2}\right)\end{array}$} \\
\hline & & & $\mathrm{N}-\mathrm{W}$ & S-W & S-E & WWR & WFR & \\
\hline \multirow{4}{*}{ First floor } & Guest room & TWL & 9.6 & 15.77 & - & 15 & 23 & 31 \\
\hline & Living room & TWL & - & 15.5 & - & 17 & 14 & 12.5 \\
\hline & Bedroom-1 & $\mathrm{HOBO}$ & - & 14.4 & 12.16 & 14 & 12 & - \\
\hline & Bedroom-2 & $\mathrm{HOBO}$ & - & - & 12.8 & 14 & 12 & - \\
\hline \multirow{4}{*}{ Second floor } & Bedroom-3 & $\mathrm{HOBO}$ & - & 14.4 & 12.16 & 6.5 & 6.1 & 17 \\
\hline & Bedroom-4 & $\mathrm{HOBO}$ & - & - & 12.8 & 7.3 & 6.1 & 18 \\
\hline & Office room & $\mathrm{HOBO}$ & - & 13.12 & - & 8.7 & 6 & 21.3 \\
\hline & Mashab room & $\mathrm{HOBO}$ & - & 9.6 & - & 60 & 75 & 9 \\
\hline Second floor (outdoor) & Terrace & TWL & - & - & - & - & - & - \\
\hline
\end{tabular}


The calibration process was done for all the equipment prior to the in-house measurements. For more rational analysis, Table 1 provides full details of all the spaces, floors and external walls and windows associated with the data logger and orientation. The Window to Wall Ratio (WWR) and Window to Floor Ratio (WFR) for each space are also mentioned in the table. This will help to elaborate the indoor thermal analysis based on the house condition.

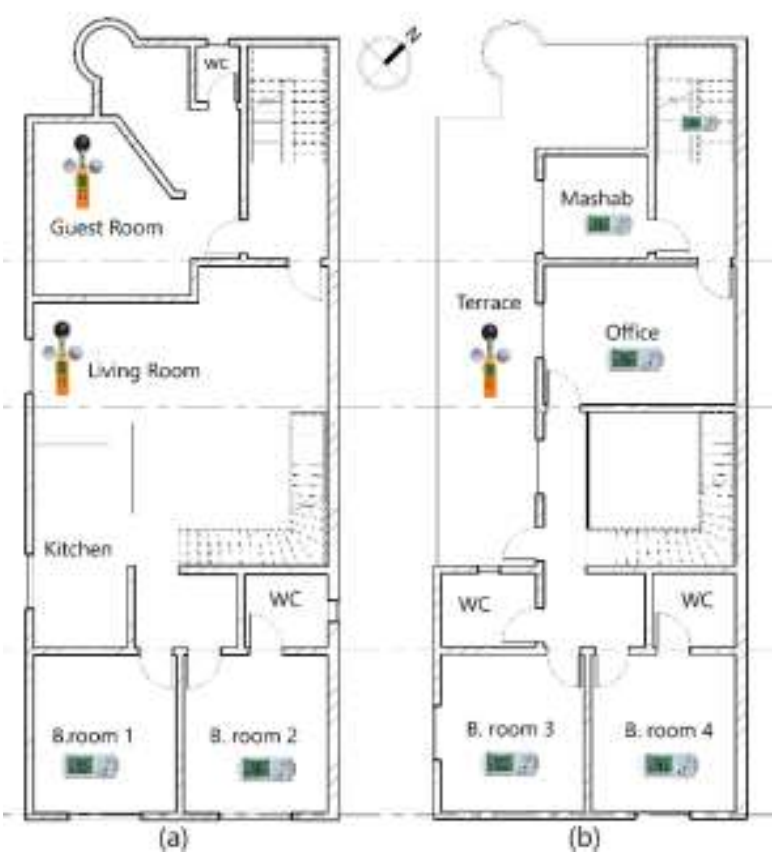

Figure 1. Typical house in Qassim region, (a) first floor, (b) second floor

\subsection{The climate zones}

According to SBC, climate zones were divided into three zones as shown in Figure 2. The thermal assessment of the house building in terms of spatial design and space arrangement was analyzed and compared based on climatic zone 2. Qassim as a desert area, has arid hot and cool weather conditions during summer and winter, respectively. However, the cooling degree days in zone 2 is between 3500 and 5000 at $10^{\circ} \mathrm{C}$.

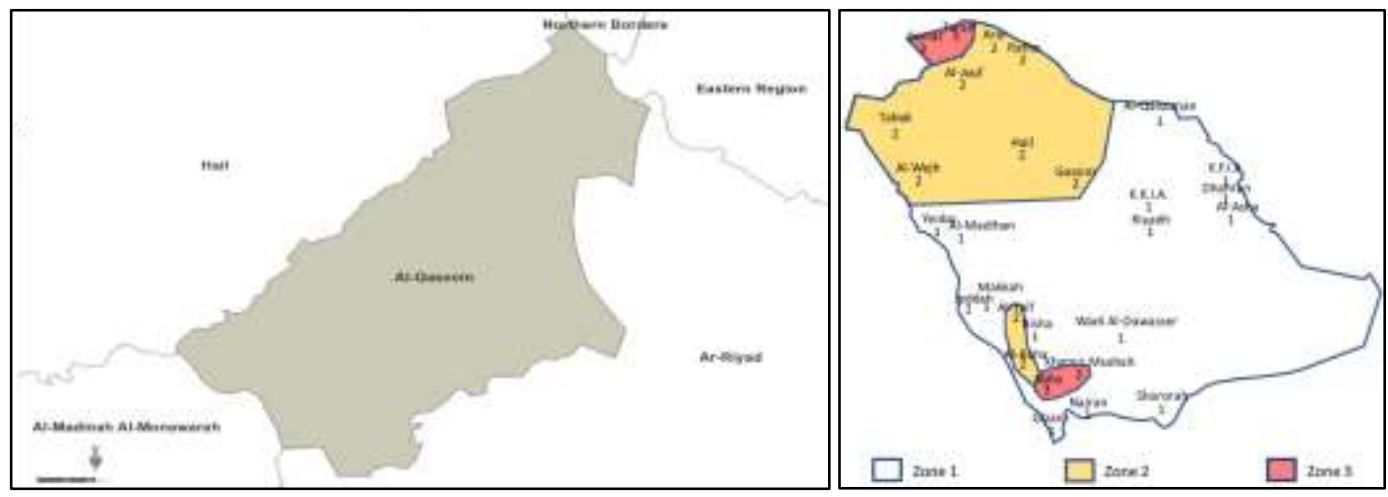

Figure 2. climate zone in Saudi Arabia based on SBC

\subsection{Findings}

In this section, the main outputs of the indoor temperature analysis are explained with respect to the house condition in terms of external wall area, exposure and windows as shown in Table1. In Figure 3, the internal air temperature is illustrated in box plots for the first floor. The figure shows the average day thermal performance inside the rooms. As can be seen, the guest room recorded the highest air temperature with $40.4^{\circ} \mathrm{C}$ compared to other spaces on the same floor. The reason can be found in Table 2 as the external walls of the guest room are exposed more to the west direction on two sides. Another reason of heat gain is the rooftop of the guest room with 31 $\mathrm{m}^{2}$ compared to the living room which has $12.5 \mathrm{~m}^{2}$ of the exposed top roof. 


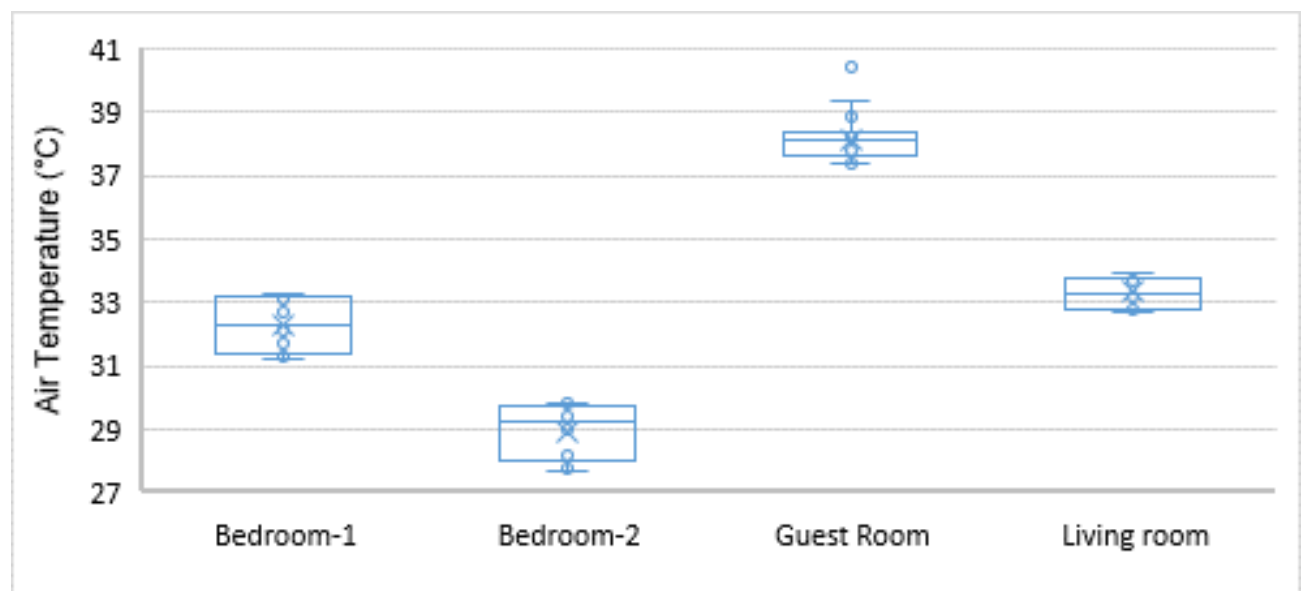

Figure 3. Box plots analysis of thermal performance for indoor spaces (first floor)

Table 2. indoor spaces temperature with wall and window characteristics (first floor)

\begin{tabular}{lccccccccc}
\hline \multirow{2}{*}{ Spaces } & \multicolumn{3}{c}{ Air Tem $\left({ }^{\circ} \mathrm{C}\right)$} & \multicolumn{3}{c}{ External Walls orientation $\left(\mathrm{m}^{2}\right)$} & \multicolumn{2}{c}{ Window $(\%)$} & \multirow{2}{*}{ Top roof $\left(\mathrm{m}^{2}\right)$} \\
\cline { 2 - 7 } & Max. & Min. & Avg. & N-W & S-W & S-E & WWR & WFR & 31 \\
\hline Guest room & 40.4 & 37.4 & 38.1 & 9.6 & 15.77 & - & 15 & 23 & 12.5 \\
Living room & 33.9 & 32.7 & 33.3 & - & 15.5 & - & 17 & 14 & - \\
Bedroom-1 & 33.3 & 31.2 & 32.2 & - & 14.4 & 12.16 & 14 & 12 & - \\
Bedroom-2 & 29.8 & 27.7 & 28.9 & - & - & 12.8 & 14 & 12 & - \\
\hline
\end{tabular}

On the other hand, bedroom-4 recorded the lowest indoor air temperature with an average value of $28.9^{\circ} \mathrm{C}$ which is $3.3^{\circ} \mathrm{C}$ lower than bedroom-3 which have the same area. As seen in Table 2, although both bedrooms have the same WWR and WFR value, bedroom 4 is exposed to outdoor only from the S-E side while bedroom 3 is exposed from S-E and S-W.

Another illustration of the indoor thermal performance can be seen in Figure 4. It is clear that the air temperature trend slightly increased through the 24 hours, specifically after $10 \mathrm{AM}$. There is a clear rise in the temperature at $1: 30$ inside the guest room until $40.4^{\circ} \mathrm{C}$, followed by a drop at $3: 30 \mathrm{PM}$ with $38.4^{\circ} \mathrm{C}$.

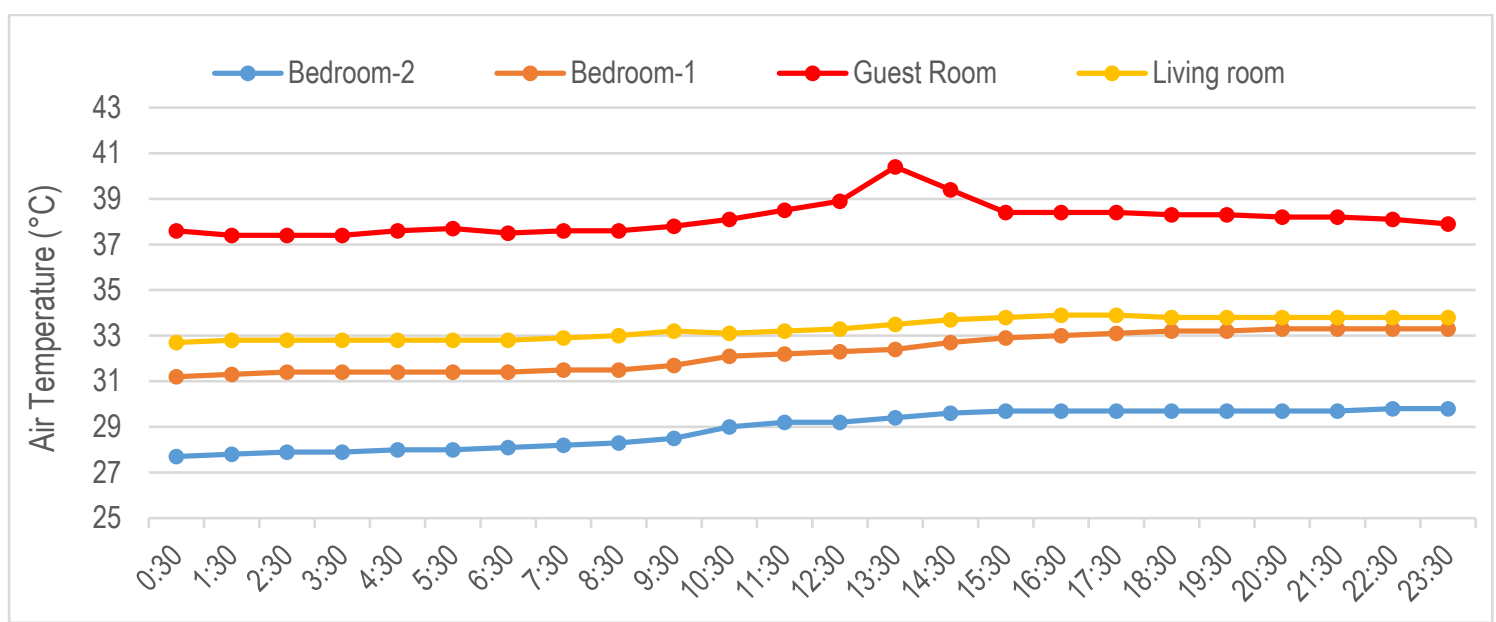

Figure 4. Indoor thermal performance (first floor)

For the second floor, as seen in Figure 5, the Mashab room recorded the highest indoor temperature with a maximum, minimum and average degree of $46.4^{\circ} \mathrm{C}, 39^{\circ} \mathrm{C}$ and $42^{\circ} \mathrm{C}$ respectively. Notably, the WWR is the main effect in such a house construction condition with respect to the existing orientation. Although the Mashab room has the lowest WFR with only one side exposed wall of 12.8 to the S-E direction, the room is very hot and cannot be habitable at all during summer without a high demand of air-conditioning. Comparing the Mashab room to the outdoor terrace, despite the temperature increasing up to the peak $\left(56.6^{\circ} \mathrm{C}\right)$ at $1: 30 \mathrm{PM}$, it is reduced to $32.4^{\circ} \mathrm{C}$ at midnight. The lowest temperature recorded inside Mashab room is $39^{\circ} \mathrm{C}$ at $6: 30 \mathrm{AM}$. 


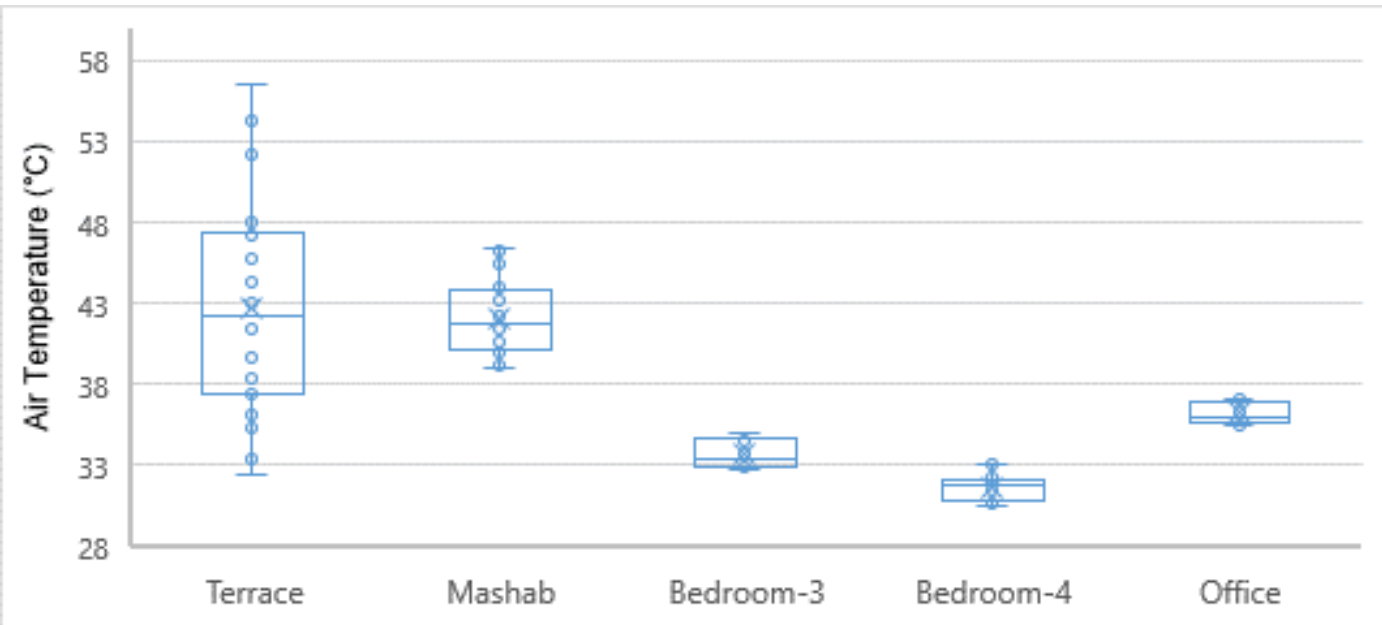

Figure 5. Box plots analysis of thermal performance for indoor spaces with outdoor terrace area (second floor)

In addition, as seen in Table 3, the office room is located beside the Mashab room with bigger WFR and smaller WWR and facing the same direction S-W. however, the air temperature recorded inside the room is lower than the Mashab room with $6^{\circ} \mathrm{C}$ average differences. In line with the bedrooms on the first floor, bedroom-4 has recorded lower air temperature than bedroom-3 which has more exposed wall area to the S-W direction. For the outdoor terrace, it is obvious that the dry-bulb temperature varies during the 24 hours with a maximum, minimum and average value of $56.6^{\circ} \mathrm{C}$ at $1: 30 \mathrm{PM}, 32.4^{\circ} \mathrm{C}$ at $0: 30 \mathrm{AM}$ and $42.7^{\circ} \mathrm{C}$ respectively.

Table 3. Indoor spaces temperature with wall and window characteristics (second floor)

\begin{tabular}{lccccccccc}
\hline \multirow{2}{*}{ Spaces } & \multicolumn{3}{c}{ Air Tem $\left({ }^{\circ} \mathrm{C}\right)$} & \multicolumn{3}{c}{ External Walls orientation $\left(\mathrm{m}^{2}\right)$} & \multicolumn{2}{c}{ Window $(\%)$} & \multirow{2}{*}{ Top roof $\left(\mathrm{m}^{2}\right)$} \\
\cline { 2 - 8 } & Max. & Min. & Avg. & N-W & S-W & S-E & WWR & WFR & 17 \\
\hline Bedroom-3 & 35 & 32.8 & 33.7 & - & 14.4 & 12.16 & 6.5 & 6.1 & 18 \\
Bedroom-4 & 33 & 30.5 & 31.7 & - & - & 12.8 & 7.3 & 6.1 & 21.3 \\
Office room & 37.1 & 33 & 36 & - & 13.12 & - & 8.7 & 6 & 9 \\
Mashab room & 46.4 & 39 & 42 & - & 9.6 & - & 60 & 75 & 9 \\
\hline
\end{tabular}

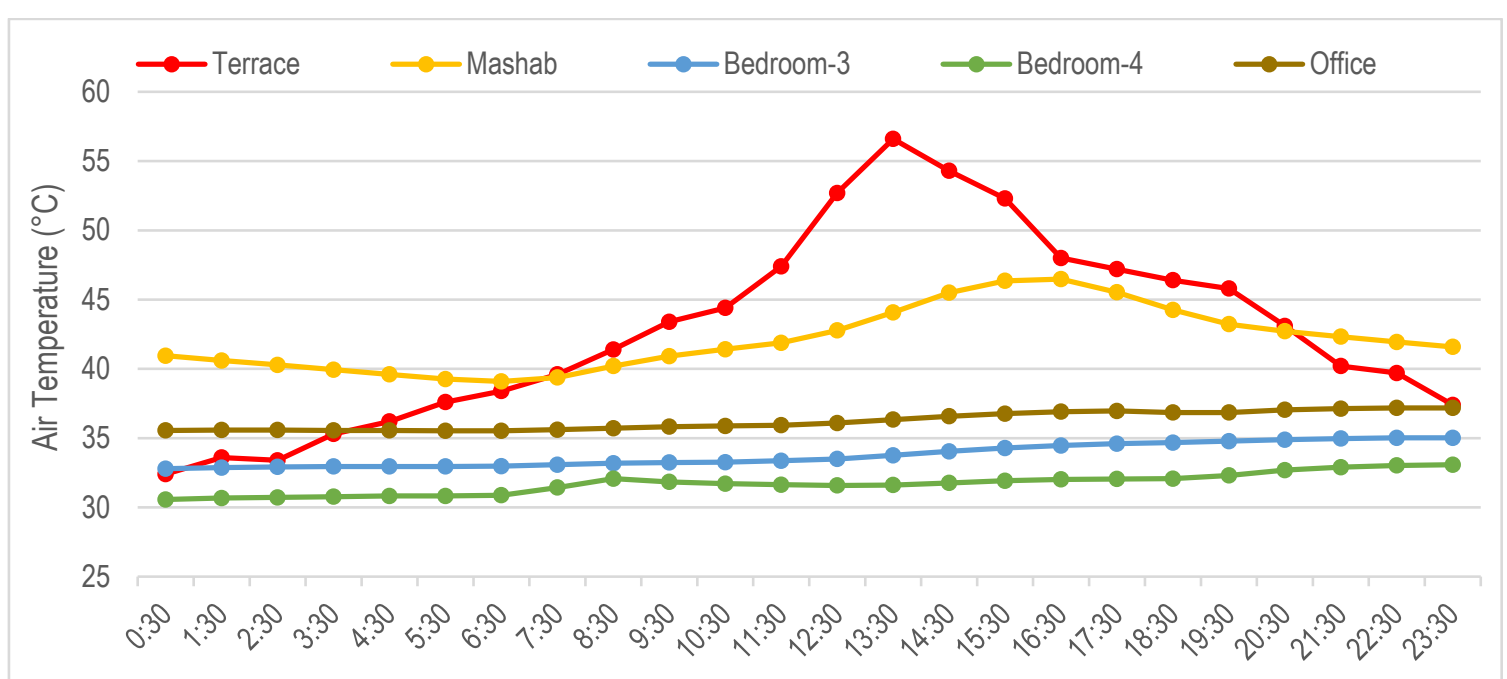

Figure 6. Indoor thermal performance with outdoor terrace area (second floor)

Looking into Figure 6, the dry bulb temperature reaches the peak at 1:30 PM while the indoor temperature for the Mashab room reaches the peak temperature at 4:30 PM. It is obvious from the figure that the outdoor temperature condition is better than the indoor temperature of the Mashab room from 8:30 PM to 6:30 AM and for the office room from 11:30 PM 3:30 AM. The temperature in the remaining rooms, bedroom-3, bedroom-4, recorded almost steady temperature during the whole 24 hours with slight increases throughout the day.

Looking into the differences between the two floors, Figure 7 shows the thermal performance in the four rooms, bedroom- 1 and bedroom-2 on the first floor and bedroom-3 and bedroom-4 on the second floor. All the rooms have the same WWR, WFR and external wall orientation. As seen in Table 4, bedroom-2 air temperature is recorded with a maximum value of $29.8^{\circ} \mathrm{C}$ while $33^{\circ} \mathrm{C}$ is recorded in the above room (bedroom-4). The bedroom-4 has an exposed top roof with an area of $18 \mathrm{~m}^{2}$ which caused the increased heat. 


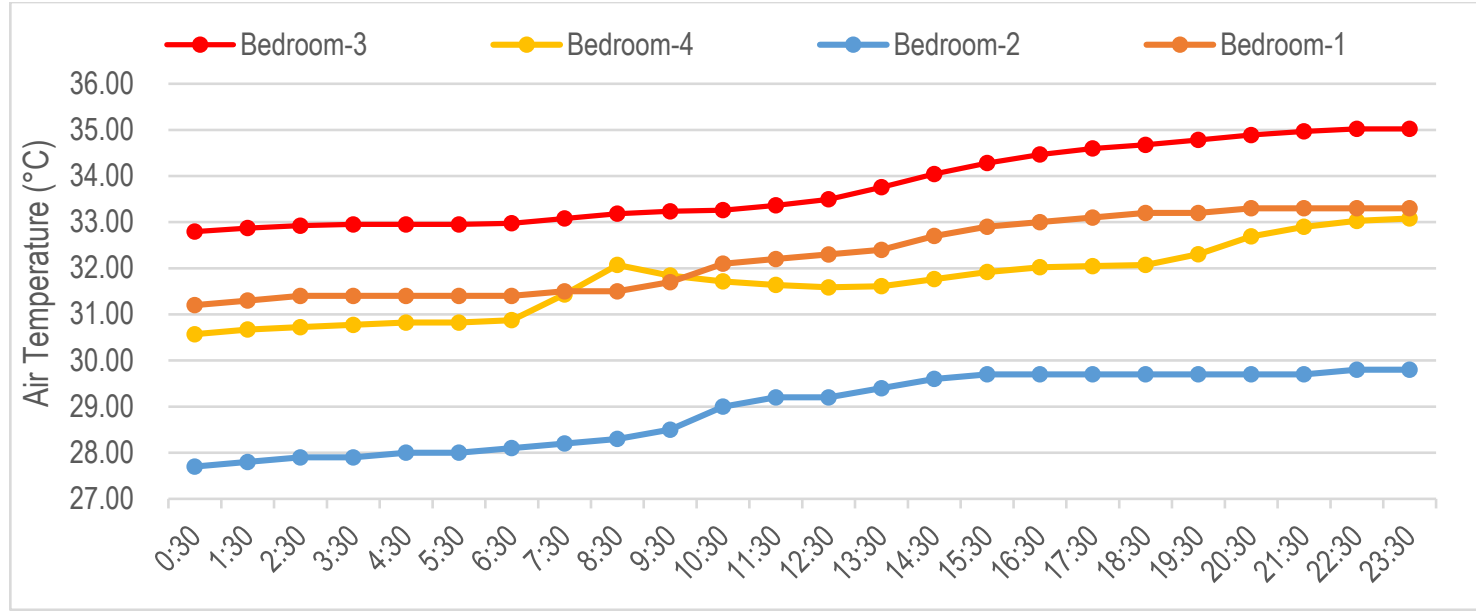

Figure 7. Indoor thermal performance for the Bedrooms on both 1st and 2nd floors

Table 4. Bedrooms air temperature with wall and window characteristics

\begin{tabular}{lccccccccc}
\hline \multirow{2}{*}{ Spaces } & \multicolumn{3}{c}{ Air Tem $\left({ }^{\circ} \mathrm{C}\right)$} & \multicolumn{3}{c}{ External Walls orientation $\left(\mathrm{m}^{2}\right)$} & \multicolumn{2}{c}{ Window $(\%)$} & \multirow{2}{*}{ Top roof $\left(\mathrm{m}^{2}\right)$} \\
\cline { 2 - 7 } & Max. & Min. & Avg. & N-W & S-W & S-E & WWR & WFR & \\
\hline Bedroom-1 & 33.3 & 31.2 & 32.2 & - & 14.4 & 12.16 & 14 & 23 & - \\
Bedroom-2 & 29.8 & 27.7 & 28.9 & - & - & 12.8 & 14 & 14 & - \\
Bedroom-3 & 35 & 32.8 & 33.7 & - & 14.4 & 12.16 & 6.5 & 6.1 & 17 \\
Bedroom-4 & 33 & 30.5 & 31.7 & - & - & 12.8 & 7.3 & 6.1 & 18 \\
\hline
\end{tabular}

Likewise, bedroom-1 and bedroom-3 have differences in thermal temperature value of $1.5^{\circ} \mathrm{C}$ on average. The trend of the temperature insides of the rooms increased gradually throughout the 24 hours (Figure 7).

\subsection{Discussion}

The presented study is an attempt to better understand the thermal behavior inside an apartment building in a dry desert area such as Qassim region. The measurements were taken on a hot day in the summer, and from the results, it was found that the temperature reached $56.6^{\circ} \mathrm{C}$ at $1: 30 \mathrm{PM}$. Although this was extremely hot for human habitat and no one can stand such a heat according to scale and temperature threshold of specific thermal sensation in some indices such as Universal Thermal Climate Index (UTCI), Predicted Mean Vote (PMV) and WetBulb Globe Temperature (WBGT). As illustrated in Figure 6, for quite a number of hours, the temperature was below the indoor temperature in some indoor rooms which reflect the low quality of the house envelope and, thus, the high chance of heat gain.

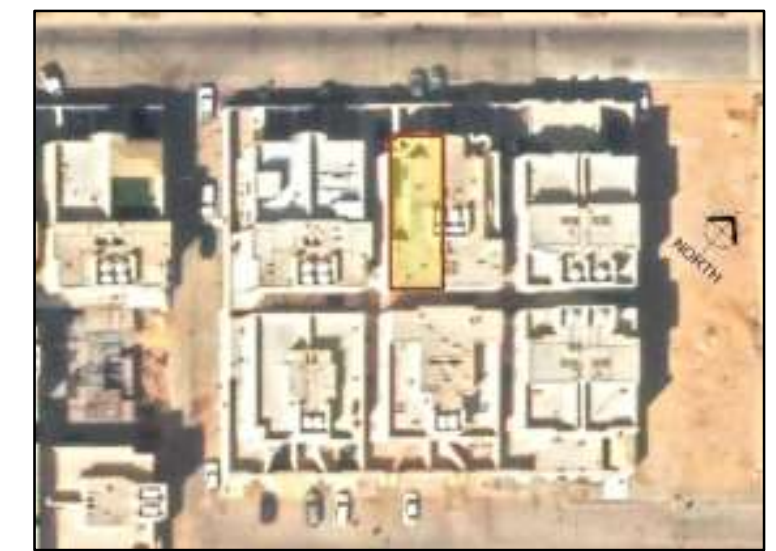

Figure 8. Top view of the surrounding fabric conditions of the case study

On the other hand, in Table 4, it is clear how rooftop and wall exposure played a significant effect on the indoor thermal performance which indicate the importance of addressing U-value for those elements particularly. As seen in Figure 8, the main façade of the house is S-W which is considered an undesirable solution design option based on some studies (Alwetaishi, 2019).

It is also a good approach to study the surrounding fabric conditions (Figure 8) of all types of man-made and natural made that could have a thermal effect on the targeted building. These are like shadow behavior during the year and wind direction and speed. Besides the climatic aspects and orientation options, architects and designers should make the decision based on existing physical conditions 
in terms of spaces in between, number of floors and façade treatment. This will help in identifying the most appropriate internal spaces function as well as the appropriate U-value for façade/ roof elements.

\subsection{Conclusion}

In a nutshell, the conclusion can be drawn as follow:

- In Qassim region, Space facing southern and western directions should be avoided or assigned for seasonal or partly used such as a guest room.

- It is good to provide alternative space for seasonal use, e.g. guest room that faces west can be utilized during winter, while a living room that faces north can be utilized during summer.

- Surrounding fabric significantly affect the indoor temperature due to the shadows cast. Especially in the lower

- Although desired land orientation is not an option in many residential neighbourhoods, based on these results, it is possible to focus on the hottest spaces to be taken into account through appropriate selection of $\mathrm{U}$-value for house envelopes, including walls, windows and roofs.

\section{Acknowledgements}

Special thanks to the architecture department and the deanship of scientific research in Qassim university as they help in providing the equipment for data collections.

\section{Paper Contribution to Related Field of Study}

In Qassim region, there is a lack of research on indoor thermal behaviors in residential buildings. Future work can be done the other building which faces North and East. A simulation could be a remarkable method to highlight more possible variables.

\section{References}

2030 Vision. (2020). Energy \& Sustainability - Vision 2030. https://www.vision2030.gov.sa/thekingdom/explore/energy/

Abd-ur-Rehman, H. M., Al-Sulaiman, F. A., Mehmood, A., Shakir, S., \& Umer, M. (2018). The potential of energy savings and the prospects of cleaner energy production by solar energy integration in the residential buildings of Saudi Arabia. Journal of Cleaner Production, 183, 1122-1130. https://doi.org/10.1016/J.JCLEPRO.2018.02.187

Abdul Mujeebu, M., \& Alshamrani, O. S. (2016). Prospects of energy conservation and management in buildings - The Saudi Arabian scenario versus global trends. In Renewable and Sustainable Energy Reviews (Vol. 58, pp. 1647-1663). Pergamon. https://doi.org/10.1016/j.rser.2015.12.327

Akbari, P., Yazdanfar, S.-A., Hosseini, S.-B., \& Norouzian-Maleki, S. (2021). Housing and mental health during outbreak of COVID-19. Journal of Building Engineering, 43, 102919. https://doi.org/10.1016/J.JOBE.2021.102919

Al-Homoud, M. S., \& Krarti, M. (2021). Energy efficiency of residential buildings in the kingdom of Saudi Arabia: Review of status and future roadmap. Journal of Building Engineering, 36, 102143. https://doi.org/10.1016/j.jobe.2020.102143

Alayed, E., O'hegarty, R., \& Kinnane, O. (2021). Thermal envelope analysis for new code compliance of Saudi Arabian dwellings. Energy and Buildings, $243,110997$. https://doi.org/10.1016/j.enbuild.2021.110997

Aldubyan, M., \& Krarti, M. (2022). Impact of stay home living on energy demand of residential buildings: Saudi Arabian case study. Energy, 238. https://doi.org/10.1016/j.energy.2021.121637

Alwetaishi, M. (2019). Impact of glazing to wall ratio in various climatic regions: A case study. Journal of King Saud University - Engineering Sciences, $31(1), 6-18$. https://doi.org/10.1016/j.jksues.2017.03.001

Alwetaishi, M., \& Benjeddou, O. (2021). Impact of window to wall ratio on energy loads in hot regions: A study of building energy performance. Energies, 14(4), 1080. https://doi.org/10.3390/en14041080

Asif, M. (2016). Growth and sustainability trends in the buildings sector in the GCC region with particular reference to the KSA and UAE. Renewable and Sustainable Energy Reviews, 55, 1267-1273. https://doi.org/10.1016/J.RSER.2015.05.042

Fernández-Agüera, J., Domínguez-Amarillo, S., Alonso, C., \& Martín-Consuegra, F. (2019). Thermal comfort and indoor air quality in low-income housing in Spain: The influence of airtightness and occupant behaviour. Energy and Buildings, 199, 102-114. https://doi.org/10.1016/j.enbuild.2019.06.052

Ghamdi, A. Al. (2020). Saudi Arabia Energy Report. King Abdullah Petroleum Studies and Research Center, November. https://www.kapsarc.org/research/publications/saudi-arabia-energy-report/

Hailu, H., Gelan, E., \& Girma, Y. (2021). Indoor Thermal Comfort Analysis: A Case Study of Modern and Traditional Buildings in Hot-Arid Climatic Region of Ethiopia. Urban Science 2021, Vol. 5, Page 53, 5(3), 53. https://doi.org/10.3390/URBANSCI5030053

Kong, M., Dong, B., Zhang, R., \& O'Neill, Z. (2022). HVAC energy savings, thermal comfort and air quality for occupant-centric control through a side-by-side 
experimental study. Applied Energy, 306. https://doi.org/10.1016/j.apenergy.2021.117987

Licina, D., \& Yildirim, S. (2021). Occupant satisfaction with indoor environmental quality, sick building syndrome (SBS) symptoms and self-reported productivity before and after relocation into WELL-certified office buildings. Building and Environment, 204. https://doi.org/10.1016/j.buildenv.2021.108183

Saudi Energy Efficiency Center. Saudi Energy Efficiency Center (SEEC). Retrieved September 4, 2021, from https://www.seec.gov.sa/en/

USEPA. (2013). US EPA@ Indoor Air Quality (IAQ). https://www.epa.gov/report-environment/indoor-air-qualityXu, C., Luo, X., Yu, C., \& Cao, S.-J. (2020). The 2019-

$\mathrm{nCoV}$ epidemic control strategies and future challenges of building healthy smart cities. Indoor and Built Environment, $1420326 \mathrm{X} 2091040$. https://doi.org/10.1177/1420326x20910408 